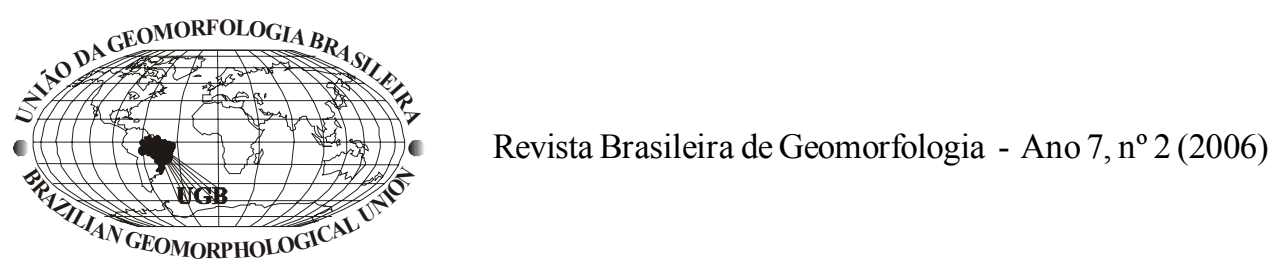

\title{
MAPEAMENTO GEOMORFOLÓGICO DO ESTADO DO PARANÁ ${ }^{1}$
}

\author{
Leonardo José Cordeiro Santos \\ Professor Doutor - Universidade Federal do Paraná (UFPR) \\ santos@ufpr.br \\ Chisato Oka-Fiori \\ Professora Doutora - Universidade Federal do Paraná (UFPR) \\ chisato@ufpr.br \\ Naldy Emerson Canali \\ Professor Doutor - Universidade Federal do Paraná (UFPR) \\ naldy@brturbo.com.br \\ Alberto Pio Fiori \\ Professor Doutor - Universidade Federal do Paraná (UFPR) \\ piofiori@terra.com.br
}

Claudinei Taborda da Silveira

Doutorando em Geografia - Universidade Federal do Paraná (UFPR) claudineits@pop.com.br

Julio Manoel França da Silva

Graduado em Geografia - Universidade Federal do Paraná (UFPR) juliogeog@yahoo.com.br

Jurandyr Luciano Sanches Ross

Professor Doutor - Universidade de São Paulo (USP)

juraross@usp.br

\section{Resumo}

O mapeamento geomorfológico do estado do Paraná procurou seguir em grande parte a metodologia adotada por Ross (1977) para o estado de São Paulo, a fim de dar seqüência a uma sistematização de uma cartografia geomorfológica regional. A escala adotada, 1: 250000, permitiu a utilização dos três primeiros taxons, ou seja, representação cartográfica das Unidades Morfoestruturais, Unidades Morfoesculturais e Sub-unidades Morfoesculturais. No $1^{\circ}$ taxon foram identificadas as unidades morfoestruturais: Cinturão Orogênico do Atlântico; Bacia Sedimentar do Paraná e Bacias Sedimentares Cenozóicas e Depressões Tectônicas. No $2^{\circ}$ taxon foram identificadas as unidades morfoesculturais: Serra do Mar e Morros Isolados e Primeiro Planalto Paranaense; Segundo Planalto e Terceiro Planalto; Planície Litorânea e Flúvio-Marinhas e Planícies Fluviais. No $3^{\circ}$ taxon foram mapeadas cinqüenta subunidades morfoesculturais. Este trabalho objetiva atender a demanda por uma base geomorfológica sistemática para informar ao sistema de planejamento do Estado do Paraná, bem como aos estudos de geologia, zoneamento ecológico-econômico e recursos hídricos, entre outros.

Palavras-chave: mapeamento geomorfológico, mapa do Paraná, geomorfologia aplicada

\footnotetext{
${ }^{1}$ Parte do Atlas "Mapeamento Geomorfológico do Estado do Paraná", publicado em novembro de 2007 pelo convênio estabelecido entre a Minerais do Paraná - MINEROPAR S/A e o Laboratório de Hidrogeomorfologia - LHG, do Departamento de Geografia da Universidade Federal do Paraná
} 


\begin{abstract}
The geomorfological mapping of the state of Paraná tried to follow the methodology adopted by Ross (1977) for the state of São Paulo, in order to give sequence to a systemization of a regional geomorfological cartography. The adopted scale, 1:250000 allowed the use of the first 3 taxons, in other words, cartographic representation of the Morfoestructural Units, Morfoescultural Units and Morfoescultural Sub-units. In the first taxon were identified the morfoestructurals units: the Atlantic Orogenic Belt; the Sedimentary Paraná Basin and Sedimentary Cenozoic's Basins and Tectonics Depressions. In the second táxon were identified the morfoesculturals units: the Atlantic Sea's Range, Isolated mountain range and the Paraná First; Second and Third Plateau; Coast Plain, Alluvial Plain and Alluvial-sea Plain. In the third taxon were mapped 50 morfoesculturals sub-units. This work will assist the demand for a geomorfological systematic basin to inform to the system of planning of the state as well as to the geology studies, ecological-economical zoning, hidric resources, among others.
\end{abstract}

Keywords: geomorfological mapping - map of the State of Paraná - applied geomorphology

\section{Introdução}

A cartografia geomorfológica é entendida como um importante instrumento na representação do relevo da superfície terrestre e segundo muitos autores (Tricart, 1965; Libault, 1975; Chorley \& Haggett, 1975) se constitui num dos principais métodos para o estudo e a pesquisa em geomorfologia, mas também pode ser utilizada no planejamento ambiental (Ross, 1990), fornecendo informações sobre as potencialidades, vulnerabilidades, restrições e riscos de ocupação e intervenções possíveis na paisagem.

Entretanto, o relevo apresenta uma diversidade de formas e de processos que associados principalmente às características geológicas e climáticas predominantes, torna complexa a tarefa de representá-lo em um único documento. Pode-se associar a estas dificuldades, os diferentes procedimentos técnicos, a escala de trabalho e o objetivo do pesquisador (Cunha et al, 2003).

A análise geomorfológica, quando considera as influências do substrato geológico na formação e configuração do relevo, este pode ser representado cartograficamente por unidades morfoestruturais. Já quando se considera a natureza das rochas em relação à ação intempérica, resultam as unidades morfoesculturais (Ross, 1990).

Ross (1990) aponta a padronização ou uniformização da representação cartográfica como a mais problemática. Segundo ele, ao contrário de outros mapas temáticos, ainda não se conseguiu chegar a um modelo de representação que satisfaça os diferentes interesses dos estudos geomorfológicos.

Para Kohler (2002), a noção de escala é fundamental na cartografia geomorfológica, determinando a adoção de diferentes estratégias e técnicas de abordagem. Ross (1990), da mesma forma, destaca a importância da escala de tratamento ou de representação do relevo no grau de detalhamento ou de generalização da informação. Por exemplo, as cartas de grande escala permitem mapear formas de relevo em nível local, bem como processos atuais, enquanto os mapas de pequena escala permitem mapear, principalmente, unidades morfoestruturais e unidades morfoesculturais.

Frente ao exposto, e no sentido de complementar os trabalhos pioneiros desenvolvidos por Reinhard Maack na primeira metade do século passado, que possibilitou a primeira divisão do relevo do estado do Paraná em unidades naturais (litoral, serra do mar, primeiro, segundo e terceiro planalto), a presente pesquisa teve como objetivo a realização do mapeamento geomorfológico (morfoestrutural/ morfoescultural) do Estado do Paraná. Constitui-se num marco fundamental para o estudo geomorfológico, pois foi o primeiro trabalho de cartografação sistemático realizado para todo o Estado.

Para sua execução, procurou-se utilizar uma metodologia que possibilitasse o reconhecimento e o agrupamento de formas de relevo a partir das suas características homogêneas e que estivesse associada aos conceitos de morfoestrutura e morfoescultura desenvolvidos pelos geomorfólogos russos Gerasimov (1946), Mescerjakov (1968) e Gerasimov \& Mescherikov, (1968). Assim, este mapeamento seguiu os mesmos fundamentos metodológicos dos autores citados e adotados por Ross (1997) para o Estado de São Paulo, possibilitando sua aplicação num estado vizinho com algumas feições similares, permitindo certa uniformização da representação cartográfica.

\section{Procedimentos Metodológicos}

Os procedimentos metodológicos utilizados fundamentaram-se no conceito de morfoestrutura e morfoescultura definidos nos trabalhos de Ross (1997) sobre classificação e taxonomia do relevo desenvolvidos para o Estado de São Paulo, enquanto que a metodologia de interpretação das imagens baseou-se em Soares e Fiori (1976) e de mapeamento em Oka-Fiori (2002).

A proposição de Ross (op. cit.), ressalta que a estrutura e a escultura estão presentes em qualquer tamanho de forma, embora suas categorias de tamanho, idades, gêneses e formas sejam passíveis de serem identificadas e cartografadas separadamente, portanto em categorias distintas. 
A concepção metodológica de Ross (1992), que norteou o mapeamento geomorfológico do estado de São Paulo, considera seis taxons distintos. Entretanto, foi aplicada de forma parcial neste mapeamento, visto que não é possível representar individualmente os taxons $4^{\circ}, 5^{\circ}$ e $6^{\circ}$ na escala 1:250.000 proposta para o presente estudo. Assim, os taxons utilizados foram os seguintes:

$1^{o}$ Taxon: Unidades Morfoestruturais - representadas pelo Cinturão Orogênico do Atlântico, pela Bacia Sedimentar do Paraná e pelas Bacias Sedimentares Cenozóicas e Depressões Tectônicas.

$2^{\circ}$ Taxon: Unidades Morfoesculturais - representadas pela Serra do Mar e Morros Isolados, os três Planaltos Paranaenses e Planícies contidas em cada uma das unidades morfoestruturais.

$3^{\circ}$ Taxon: Sub-unidades Morfoesculturais - representadas por formas do relevo contidas em cada uma das unidades anteriores. Embora seja este o último nível categórico abordado no trabalho, procurou-se fornecer informações do modelado dominante como dissecação, topos, tipos de vertentes, vales, gradiente altimétrico e declividade. A inclusão dessas informações visa fornecer subsídios para futuros trabalhos de planejamento do uso e ocupação do solo.

Considerou-se como elementos básicos para a definição das sub-unidades a similitude de formas de relevo relacionada aos condicionantes de natureza estrutural e litológica. O método de interpretação foi definido pelo reconhecimento dos elementos texturais e estruturais do relevo na imagem, os quais se organizam em zonas homólogas ou padrões de relevo.

Neste método a textura é representada pelos menores elementos distinguíveis visualmente na imagem (topos, encostas, vales e drenagem). As variações na textura do relevo e da drenagem constituem a propriedade fundamental na análise da imagem, pois permitem separar feições com significado diferente ou associar feições com o mesmo significado, dado pelas condições naturais. $\mathrm{O}$ arranjo dos elementos texturais pode apresentar-se com uma disposição ordenada ou aleatória; a lei que exprime ou define o padrão de organização no espaço dos elementos texturais denominase estrutura. As zonas de repartição dos elementos texturais e sua organização definem zonas homólogas ou unidade morfoestruturais.

Para Moreira (2003)

“a variação textural é analisada normalmente através de interpretação visual, que é uma sistematização de várias técnicas, as quais convergem para um único objetivo, a compartimentação da imagem. Em geral, a textura apresenta-se como sendo uma arma valiosa na interpretação de formas de relevo, drenagem e de padrões da cobertura vegetal e de uso da terra. Acredita-se que, a partir da utilização das técnicas de processamento digital de imagens e técnicas estatísticas multivariadas, como subsidiária na redução do caráter subjetivo da análise textural e da correspondência entre zonas homólogas, será possível favorecer a discriminação de elementos imageados, e encontrar um modelo que possibilite explicar mais satisfatoriamente a compartimentação e a relação de equivalência entre zonas que constituem texturas semelhantes" ( MOREIRA, 2003, p. 15).

A execução dos trabalhos de mapeamento sistemático adotado para a confecção do Mapa Geomorfológico do Estado do Paraná, seguiu as seguintes etapas:

(1) utilização dos dados do Radar SRTM (Shuttle Radar Topography Mission), com resolução de 90 metros, obtidos do site da NASA, além de mapas e cartas geológicas que compuseram um mosaico de todo estado do Paraná;

(2) conversão dos dados de SRTM para formato matricial (JPG e TIF georreferenciado) com cores em 3 bandas (RGB) e em tons de cinza;

(3) obtenção das informações de cartografia base, utilizandose das cartas topográficas 1:250.000 (IBGE) em meio digital e formato vetorial;

(4) realização de recortes do mosaico da imagem SRTM (formato matricial) para a área de abrangência de cada uma das 21 cartas que compõem todo o estado do Paraná. Utilizando-se da imagem SRTM recortada, foi iniciado o processo de delimitação dos compartimentos. Para isso, foi utilizado o método de zonas homólogas, conforme descrito anteriormente, aonde são vistas as diferenciações na superfície e assim, foram delimitadas as unidades morfoesculturais. Esse procedimento foi executado no software ArcView 3.2. Os compartimentos foram delimitados em unidades espaciais do tipo polígono, armazenados em formato matricial;

(5) elaboração de Cartas-Imagens com superposição dos limites delimitados nas unidades de relevo sobre a imagem de SRTM (em tons de cinza);

(6) confirmação em campo das áreas poligonais de cada unidade. Nessa etapa foram utilizadas as Cartas-Imagens e, com auxílio de equipamento de GPS, foram encontradas no campo cada uma das áreas delimitadas nas imagens em laboratório. Ainda nesta etapa foram descritos os compartimentos e, em cada uma das paradas, foram anotadas as coordenadas, bem como tomadas as fotografias da área $\mathrm{e}$ feita marcação do direcionamento da foto. Outras anotações referentes à descrição da paisagem e de outros aspectos relevantes foram realizadas para cada ponto de parada;

(7) realização de correções nas unidades, em laboratório. Para isso, utilizou-se dos valores das coordenadas anotadas de cada ponto de parada, os quais foram lançados no programa 
do computador e correlacionados com a base de dados do mapeamento. A partir das anotações e das fotografias, foi possível tirar dúvidas e remeter-se ao constatado em campo;

(8) quantificação dos seguintes parâmetros (realizado no software ArcView 3.2): área das unidades mapeadas; comprimento de todos os canais hidrográficos; densidade de drenagem (horizontal e vertical); gradiente altitudinal e classes de declividade (em valor de área $\mathrm{km}^{2}$ e proporção \%) para cada unidade.

\section{Resultados e Discussões}

O mapeamento geomorfológico realizado permitiu a identificação de três unidades morfoestruturais ( $1^{\circ}$ taxon), cinco unidades morfoesculturais ( $2^{\circ}$ taxon) e cinqüenta subunidades morfoesculturais ( $3^{\circ}$ taxon). (figura 1 e quadro 1 ).

As principais características dos dois primeiros níveis categóricos encontram-se descritas abaixo, enquanto que para o terceiro nível optou-se por apresentá-las no quadro mencionado, tendo em vista o grande número de unidades mapeadas. A seguir as considerações sobre as unidades morfoestruturais $\left(1^{\circ}\right.$ taxon) e suas subdivisões morfoesculturais.

\section{Cinturão Orogênico do Atlântico}

O Cinturão Orogênico do Atlântico, que no estado do Paraná ocorre em sua porção leste, é um dos mais extensos do Brasil e têm natureza poliorogênica. Desenvolve-se desde o Uruguai até o norte da Bahia, através do Rio Grande do Sul, Santa Catarina, Paraná, São Paulo, Rio de Janeiro, leste de Minas Gerais e Espírito Santo (Ross, 1987). Sua gênese vincula-se a vários ciclos geotectônicos acompanhados de sedimentação, metamorfismo regional, falhamentos, dobramentos e extensas intrusões.

Os estágios evolutivos do Cinturão Orogênico do Atlântico são ainda mal conhecidos. Ao que tudo indica, as rochas agrupam-se em núcleos metamórficos com estruturas representativas de três grandes colagens proterozóicas, vinculadas aos supercontinentes Atlântico, de idade Paleoproterozóica, Rodínia, de idade Mesoproterozóica/ Neoproterozóica e Gondwana Ocidental, do final do Neoproterozóico (Almeida e Carneiro, 1998). As sucessivas colagens e interações de placas originaram faixas móveis acrescionárias, colisionais ou transpressionais, retomadas sucessivas vezes, circundando núcleos menores, reestruturados e afetados pelas orogenias transamazônica e brasiliana (Almeida, Brito Neves e Carneiro, 2000). No estágio final do ciclo Brasiliano resultou em denso arranjo de zonas de cisalhamento dextrais anastomosadas, orientadas segundo E-NE a E-W (Hasui \& Sadowski, 1976).

A longa evolução geológica do Cinturão Orogênico do Atlântico termina com a consolidação, ou cratonização, de uma extensa área no início do Paleozóico, conhecida comoPlataforma Sul-Americana.

No Paraná é constituído por duas unidades morfoesculturais: Serra do Mar e Morros Isolados (prancha 1A) e Primeiro Planalto Paranaense. (prancha 1B).

A Serra do Mar e Morros Isolados configuram-se como uma cadeia de montanhas marginal do Primeiro Planalto Paranaense, separando-o da Planície Litorânea, com cimos elevados de até 1.800 metros de altitude, sustentada por litologias diversas, quase sempre metamórficas de alto grau, como migmatitos, gnaisses e xistos e mais raramente quartzitos, frequentemente associados com rochas intrusivas relacionadas a ciclos metamórficos mais jovens.

Rochas resistentes sustentam diversas unidades morfoestruturais dentro desta unidade morfológica, enquanto falhas, zonas de cisalhamento, fraturas e grandes domínios de rochas supracrustais condicionam lineamentos maiores e segmentos locais da rede de drenagem.

A origem da Serra do Mar é atribuída a processos tectônicos de movimentação vertical, iniciados no Cenozóico (Almeida, 1976, Asmus \& Ferrari, 1978). Dessa forma, é vista como um grande fronte dissecado de falhas em que termina o Planalto Atlântico. Devido à diversidade de tipos litológicos e padrões estruturais marcados pela superposição de diversos ciclos geotectônicos e erosivos pré e póscretácicos, pode-se identificar no Planalto Atlântico variações fisionômicas regionais, que possibilitaram delimitar sub-unidades geomorfológicas distintas: 1.1.1 Morros Isolados Costeiros, 1.1.2 Rampas de Pré-Serra e Serras isoladas, 1.1.3 Serra do Mar e 1.1.4 Blocos Soerguidos da Serra do Mar (figura 1).

O Primeiro Planalto Paranaense estende-se desde a região de Jaguariaíva, Tibagi e Purunã, nos sopés da escarpa da Serra do Purunã, constituída de estratos horizontais devonianos, até a vertente leste da Serra do Mar. Ao norte comparecem as rochas do Grupo Açungui, onde a drenagem da bacia do rio Ribeira produziu uma intensa dissecação, modelando um relevo montanhoso, com altitudes variando entre 400 e 1200 metros, sustentado por rochas metamórficas de baixo grau do Grupo Açungui, metavulcânicas do Grupo Castro, intrusões graníticas e diques de diabásio.

Ao sul é relativamente uniforme, esculpido em rochas cristalinas, tais como migmatitos, xistos metamórficos e gnaisses, cortados por diques de pegmatitos e diques de diabásio, com altitudes médias entre 850-950 metros, formando uma paisagem suavemente ondulada com planícies e várzeas intercaladas, constituídas por sedimentos colúvioaluvionares recentes e paludais ao longo dos principais cursos de água. Os sedimentos da Formação Guabirotuba preenchem a bacia de Curitiba, depositados durante o Pleistoceno e constituindo uma área de relevo de colinas que se articulam às planícies fluviais mediante suaves rampas. 


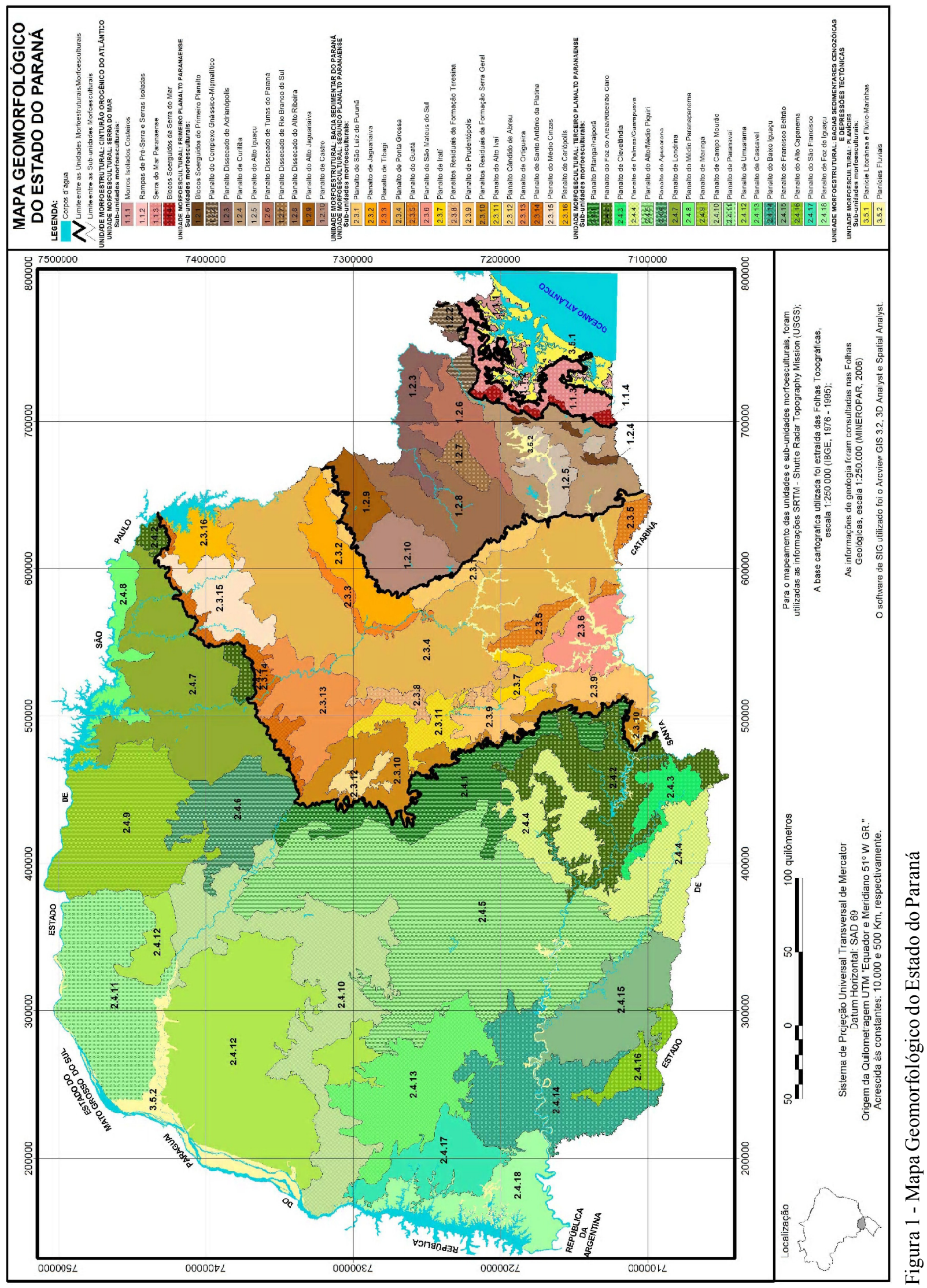




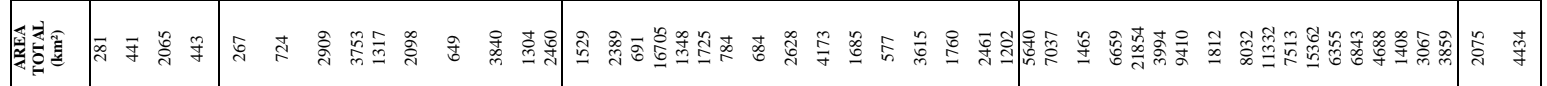

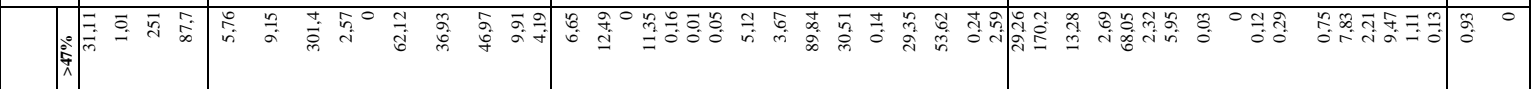

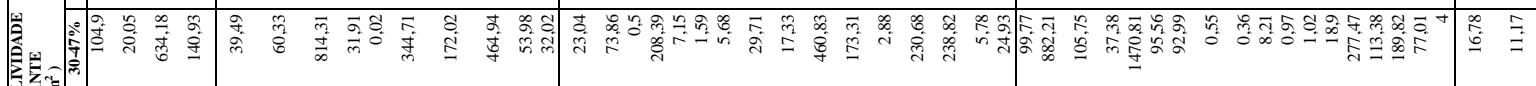

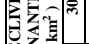

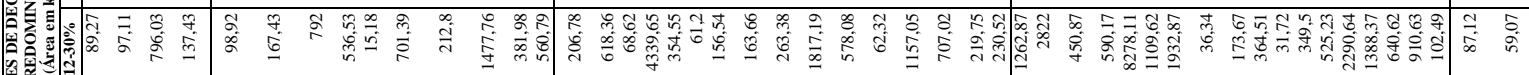

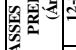

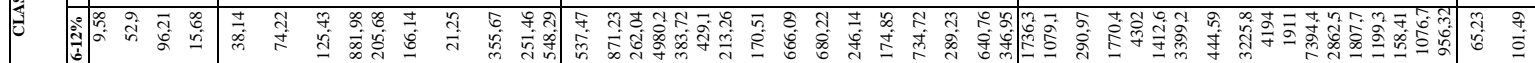

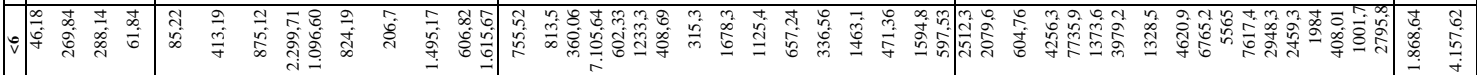

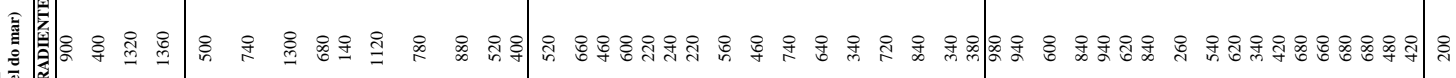
崖密部

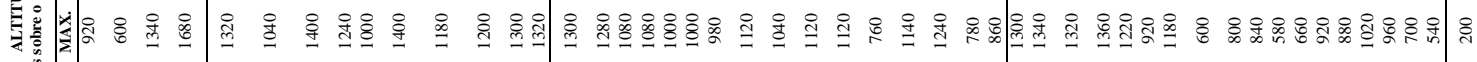

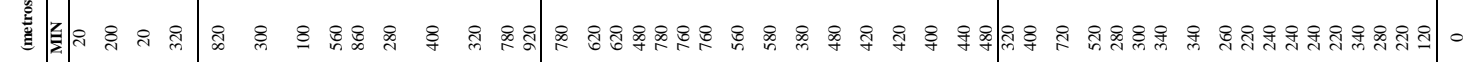

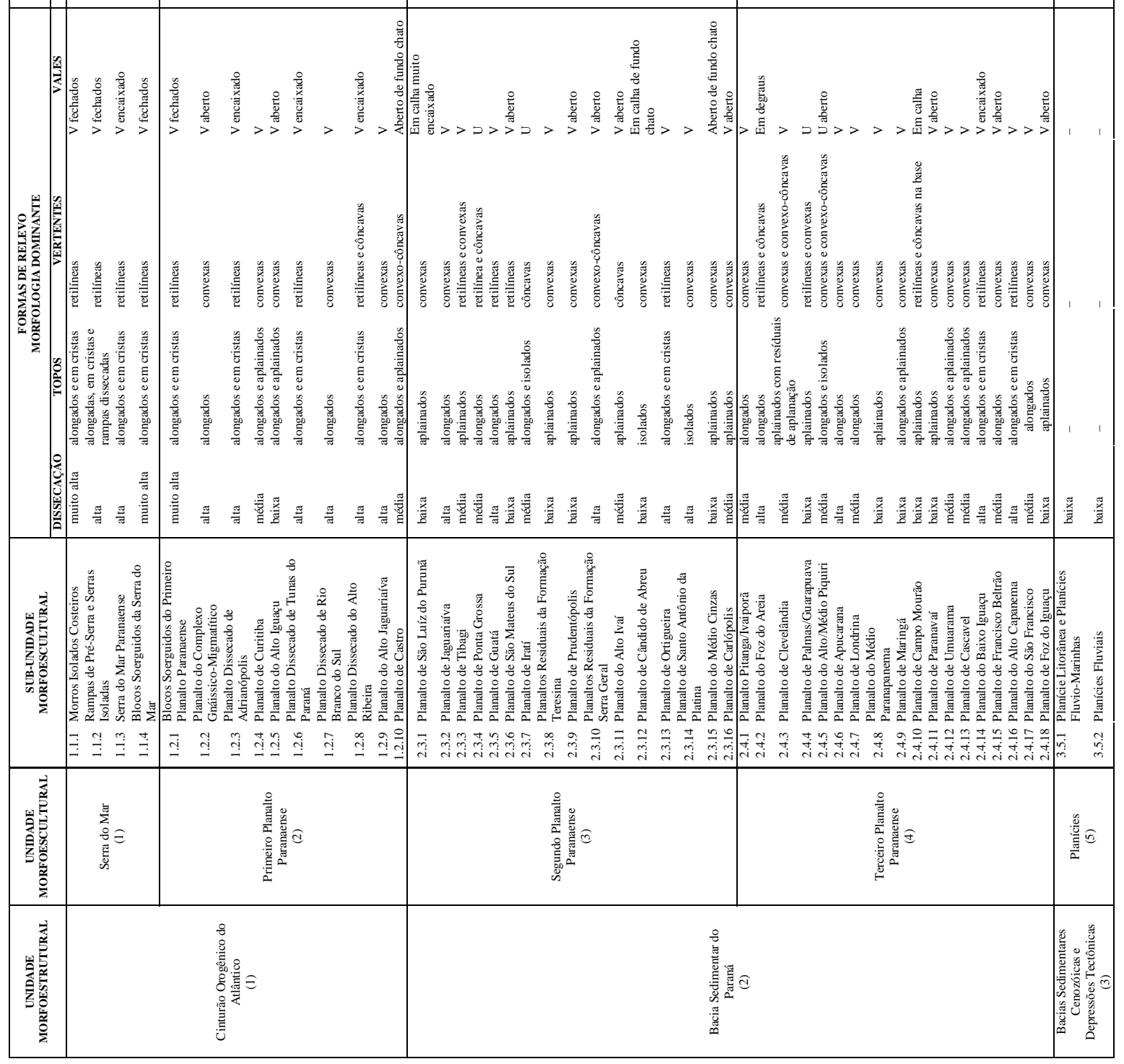



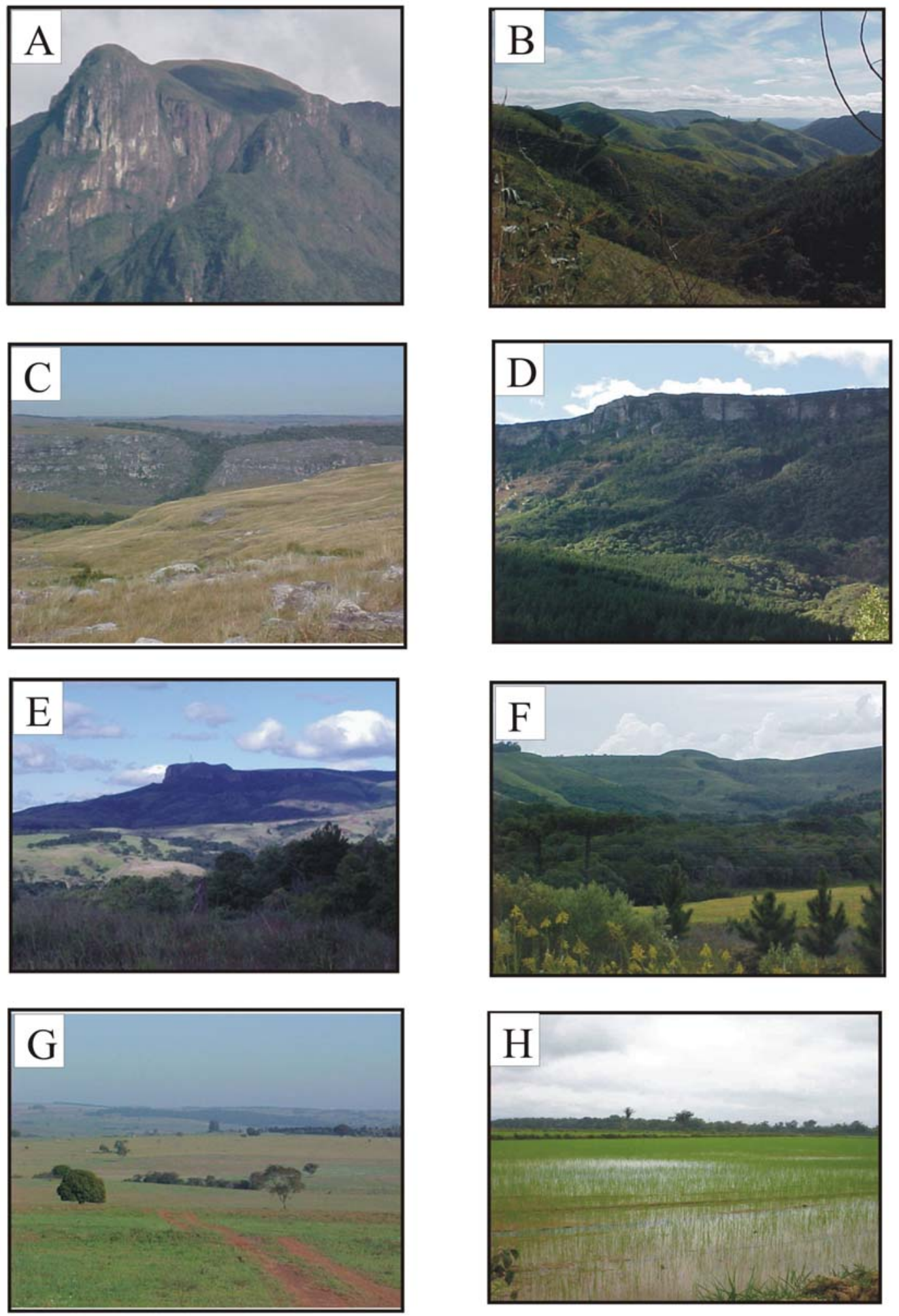

Prancha 1 - Fotos ilustrativas das unidades geomorfológicas.

Foto 1A: Serra do Mar; Foto 1B: Primeiro Planalto Paranaense; Foto 1C: Segundo Planalto Paranaense; Foto 1D: Escarpa Devoniana; Foto 1E: Escarpa Triássico-Jurássico; Foto 1F: Terceiro Planalto Basáltico; Foto 1G: Terceiro Planalto Arenítico; e Foto 1H: Planície. 
Em relação à morfogênese, Ab’Sáber \& Bigarella (1961) reconheceram dois compartimentos: (1) a Superfície Alto Iguaçu (Maack 1947, Almeida 1955), correspondente à Superfície Sul-Americana (King 1956), definida como "típica de pediplanação exorrêica”, onde a elevação isostática do escudo permitiu a erosão e a abertura de um compartimento intermontano de eversão, com um posterior aplainamento, e (2) a Superfície de Curitiba, gerada por pediplanação dominantemente endorrêica. Bigarella et al. (1965) atribuíram as superfícies aplainadas do Primeiro Planalto do Paraná a processos morfoclimáticos com alternância de climas úmidos e secos. Este planalto subdivide-se nas seguintes subunidades: 1.2.1 Blocos Soerguidos do Primeiro Planalto, 1.2.2 Planalto do Complexo Gnáissico Migmatítico, 1.2.3 Planalto Dissecado de Adrianópolis, 1.2.4 Planalto de Curitiba, 1.2.5 Planalto do Alto Iguaçu, 1.2.6 Planalto Dissecado de Tunas do Paraná, 1.2.7 Planalto Dissecado de Rio Branco do Sul, 1.2.8 Planalto Dissecado do Alto Ribeira, 1.2.9 Planalto do Alto Jaguariaiva e 1.2.10 Planalto de Castro (Figura 1).

\section{Bacia Sedimentar do Paraná}

A Bacia Sedimentar do Paraná abrange uma área de cerca de 1.600.000 $\mathrm{Km}^{2}$. Acha-se encravada na Plataforma Sul-Americana e estende-se pelos estados de Minas Gerais, Mato Grosso, São Paulo, Paraná, Santa Catarina, Rio Grande do Sul, além do Uruguai, Paraguai e Argentina. Implantou-se no Eosiluriano sobre a crosta continental do recém formado Gondwana, ainda em processo de resfriamento.

O embasamento da Bacia do Paraná é constituído principalmente de rochas cristalinas pré-Cambrianas e, subordinadamente, por rochas eo-paleozóicas afossilíferas. $\mathrm{Na}$ época de sua implantação, o sítio apresentava instabilidades tectônicas do final do ciclo Orogênico Brasiliano, associadas às zonas de fraqueza das mais variadas direções, mas concentradas, principalmente, em duas direções preferenciais N45-60W e N50-70E, que passariam a ter forte influência no desenvolvimento da própria bacia. A bacia encontra-se preenchida por depósitos marinhos e continentais com idades desde o Siluriano Superior (Formação Furnas) até o Cretácio (Grupo Bauru).

Sobre esta grande unidade morfoestrutural, no território paranaense, podem-se distinguir duas subunidades morfoesculturais: o Segundo e o Terceiro Planalto Parananese.

O Segundo Planalto Parananese (prancha 1C) encontra-se esculpido na faixa de rochas Paleozóicas e apresenta-se, no Paraná, como um planalto modelado em estruturas monoclinais, sub-horizontais, mergulhando para o oeste. Tem seus limites entre a escarpa Devoniana (prancha 1D) a leste, onde as altitudes médias de cimeira estão entre 1100 a $1200 \mathrm{~m}$ e, a oeste, com a escarpa arenito-basáltica ou Triássico-Jurássico (prancha 1E) onde, em suas proximidades, as altitudes variam entre 350 e 1200 metros s.n.m. Apresenta as seguintes sub-unidades morfoesculturais: 2.3.1 Planalto de São Luiz do Purunã, 2.3.2 Planalto de Jaguariaíva, 2.3.3 Planalto de Tibagi, 2.3.4 Planalto de Ponta Grossa, 2.3.5 Planalto do Guatá, 2.3.6 Planalto de São Mateus do Sul, 2.3.7 Planalto de Irati, 2.3.8 Planaltos Resíduais da Formação Teresina, 2.3.9 Planalto de Prudentópolis, 2.3.10 Planaltos Resíduais da Formação Serra Geral, 2.3.11 Planalto do Alto Ivaí, 2.3.12 Planalto Cândido de Abreu, 2.3.13 Planalto de Ortigueira, 2.3.14 Planalto de Santo Antônio da Platina, 2.3.15 Planalto do Médio Cinzas e 2.3.16 Planalto de Carlópolis.

O Terceiro Planalto Paranaense (ou Planalto ArenitoBasáltico) corresponde ao grande derrame mesozóico de rochas eruptivas básicas (prancha $1 \mathrm{~F}$ ) associados, na porção NO, às rochas areníticas do Grupo Bauru (prancha 1G). Abrange cerca de 2/3 do território paranaense e desenvolvese como um conjunto de relevos planálticos, com inclinação geral para oeste-noroeste e subdivididos pelos principais afluentes do rio Paraná, atingindo altitudes médias de cimeira de 1100 a 1250m, na Serra da Esperança, declinando para altitudes entre 220 e 300 metros na calha do rio Paraná. Este planalto subdivide-se nas seguintes sub-unidades: 2.4.1 Planalto Pitanga/Ivaiporã, 2.4.2 Planalto do Foz do Areia/ Ribeirão Claro, 2.4.3 Planalto de Clevelândia, 2.4.4 Planalto de Palmas/Guarapuava, 2.4.5 Planalto do Alto/ Médio Piquiri, 2.4.6 Planalto de Apucarana, 2.4.7 Planalto de Londrina, 2.4.8 Planalto do Médio Paranapanema, 2.4.9 Planalto de Maringá, 2.4.10 Planalto de Campo Mourão, 2.4.11 Planalto de Paranavaí, 2.4.12 Planalto de Umuarama, 2.4.13 Planalto de Cascavel, 2.4.14 Planalto do Baixo Iguaçu, 2.4.15 Planalto de Francisco Beltrão, 2.4.16 Planalto do Alto Capanema, 2.4.17 Planalto do São Francisco e 2.4.18 Planalto de Foz do Iguaçu.

\section{Bacias Sedimentares Cenozóicas e Depressões Tectônicas}

As morfoestruturas aqui denominadas por Bacias Sedimentares Cenozóicas e Depressões Tectônicas foram subdivididas em duas unidades morfoesculturais distintas: 3.5.1 Planície Litorânea e Planícies Fluvio-Marinhas (prancha $1 \mathrm{H}$ ) e 3.5.2 Planícies Fluviais.

\section{Considerações Finais}

O mapeamento geomorfológico realizado demonstra, com a caracterização das cinqüenta sub-unidades morfoesculturais, a complexidade do relevo paranaense, a partir da análise das interações entre as formas de relevo, natureza das rochas, eventos tectônicos e sua dinâmica morfogenética.

Esse trabalho fornece instrumentos apropriados para embasar o planejamento da paisagem paranaense no âmbito regional em unidades homogêneas que permitem definir 
potencialidades e restrições de uso, bem como dado básico de entrada para outras pesquisas ou ainda para fins didáticos.

Finalmente, o que se deseja com este mapeamento que ora se oferece é que o mesmo possa abrir perspectivas para outras iniciativas semelhantes, contribuindo para aperfeiçoálo e estimular estudos em escala de detalhe no campo da geomorfologia e de interações com a geografia e as ciências ambientais, dentre outras.

\section{Referências Bibliográficas}

Ab'Saber, A. N.; Bigarella, J. J. (1961) Superfícies aplainadas do primeiro planalto do Paraná. Boletim Paranaense de Geografia, Curitiba, n. 4-5, p. 116-125.

Ab'Saber, A. N. (1970) Províncias geológicas e domínios morfoclimáticos no Brasil. Geomorfologia, São Paulo, n. 20, p. 1-26.

Almeida, F. F. M. (1955) As camadas de São Paulo e a tectônica da Serra da Cantareira. Boletim da SBG, 4(2):23-40.

Almeida, F. F. M. (1976) Estruturas do Pré-cambriano inferior brasileiro. In: Congresso Brasileiro de Geologia, 29, 1976, Ouro Preto. Resumos... São Paulo: SBG. p. 201-202.

Almeida, F. F. M.; Carneiro, C. D. R. (1998) Origem e evolução da Serra do Mar. Revista Brasileira de Geociências, 28(2): 135-. 150.

Almeida, F. F. M.; Brito Neves, B. B.; Carneiro, C. D. R. (2000) The origin and evolution of the South American Platform. Earth-Science Reviews, Holanda, v. 50, p. $77-111$.

Asmus, H.E., Ferrari, A.L. (1978) Hipótese sobre a causa do tectonismo cenozóico na Região Sudeste do Brasil. Série Projeto REMAC, Rio de Janeiro, 4:75-88.

Chorley, R.J.; Haggat, P. (1975) Modelos Físicos e de Informação em Geografia. Rio de Janeiro, Ed.da USP - Livros Técnicos e Cientítificos.

Cunha, C.M.L., Mendes, I.A., \& Sanchez, M.C. (2003) A Cartografia do Relevo: Uma Análise Comparativa de Técnicas para a Gestão Ambiental. Rev. Bras. de Geomorfologia, Uberlândia:UFU, ano 4, ${ }^{\circ} 1$, p. 01-01.

Gerasimov, I.P. (1946) Essai d'interprétation geomorphologique du schéma general de la structure geologique de 1'URSS. Problèmes de Geographie Physique, Vol. 12, Tzd. Vo AN SSSR, Moscou.
Gerasimov, I.P. \& Mescherikov, J.A. (1968) Morphostructure. In The encyclopedia of geomorphology. Ed. R.W. Fairbridge, 731-732, New York:Reinhold Book Co.

Hasui, Y. \& Sa, G.R. (1976) Evolução geológica do PréCambriano na Região Sudeste do Estado de SãoPaulo. Revista Brasileira de Geociências, v. 6, n. 3, p. 182-200.

King, L. (1956) A Geomorfologia do Brasil Oriental, Rev. Bras. de Geografia, Rio de Janeiro, XVIII(2): 147-265.

Kohler, C.H. (2002) A Escala na Análise Geomorfológica.Rev. Bras.de Geomorfologia, Uberlândia:UFU, ano 3, no1, p. 21-31.

Libaut, A. Geocartografia. São Paulo, Cia. Ed. Nacional -Ed. da Univ. de S.Paulo, 1975.

Maack, R. (1947) Breves notícias sobre a geologia dos estados do Paraná e de Santa Catarina. Arquivos de Biologia e Tecnologia, Curitiba, v. 2, p. 63-154.

Maack, R. (1981) Geografia Física do Estado do Paraná. 2a . Edição, Curitiba, Liv. José Olympio Edit..

Mescerjakov, J. P. (1968) Lês concepts de morphoestruture et de moresculture: um nouvel instrument de 1'analyse geomorphologique. Annales de Geographie, 77 années, n.423: 539-552, Paris.

Moreira, M.R. (2003) Avaliação dos aspectos texturais na imagem Landsat como subsídio a compartimentação fisiográfica dos municípios de Peruíbe e Itanhaém - SP. 2003. 129 f. Dissertação (Mestrado em Geociências e Meio Ambiente) Instituto de Geociências e Ciências Exatas, Universidade Estadual Paulista, Rio Claro, p. 15.

Oka-Fiori, C. (2002) Geomorfologia e Dinâmica TêmporoEspacial da Bacia do Rio Itiquira, Pantanal Matogrossense-MT, MS. Tese (Doutorado) UNESP. 2002.209 p.

Ross, J.L.S. (1985) Relevo Brasileiro: uma nova proposta de classificação. Revista do Departamento de Geografia, São Paulo n 4, p. 25-39.

Ross, J. L. S. (1987) Estudo e Cartografia Geomorfológica da Província Serrana - MT - Tese de doutorado apresentada á FFLCH-USP, S. Paulo, 323p.

Ross, J. L. S. (1990) Geomorofologia, Ambiente e Planejamento. S. Paulo, Ed. Contexto

Ross, J. L. S.; MOROZ, I. C. (1996) Mapa Geomorfológico do Estado de São Paulo. Revista do Departamento de Geografia-FFCH/USP, São Paulo, v. 10, p. 20-32. 
Soares, P.C. e Fiori, A.P. (1976) Lógica e Sistemática na Análise eInterpretação de Fotografias Aéreas em Geologia. Not. Geomorfológica, Campinas, v. 16, n. 32, p. $71-104$.

Shuttler Radar Topography Mission. Imagens de radar.
Disponível em http://srtm.usgs.gov. Acesso em julho de 2004.

Tricart, J. (1965) Pricipes et Méthodes de la Geomorphologie. Paris Masson et Cie. Edit.

Tricart, J. (1977) Ecodinâmica. FIBGE/Supren, Rio de Janeiro. 